\title{
Dynamic study of cervical cancer incidence and mortality in Tashkent city
}

\begin{abstract}
The purpose of this work is to assess the epidemiological features of incidence and mortality from cervical cancer (CC) in the city of Tashkent, based on a retrospective study from 2009 to 2016. In the period under study, 1,190 new cases and 722 deaths from cervical cancer were registered in Tashkent. The average age of the patients was 54.5 years, the deceased 59.9. It was found that the age-standardized rates of CC were $11.4 \%{ }_{0000}$, mortality $-6.9 \%$. The age peak of the incidence was observed in $45-64$ years $\left(30.7 \%{ }_{0000}\right)$, and the peak of mortality in 65 years and older is $28.4^{\%} / 0000$. Trends in the age-specific morbidity and mortality rates in Tashkent had a different trend, which affected the increase in the incidence rate and the decrease in the death rate as a whole for the entire female population of the capital.
\end{abstract}

Keywords: cervical cancer, incidence, mortality, Uzbekistan, Tashkent city
Volume 8 Issue 2 - 2019

\author{
Almuhamedova BG,' Alieva DA, ${ }^{2,4}$ \\ Tillashaykhov MN, ${ }^{2}$ Igissinov NS, ${ }^{3,4}$ Yusupov \\ $\mathrm{BD}^{2}$ \\ 'Tashkent City Branch of the Republican Specialized Scientific \\ and Practical Medical Center of Oncology and Radiology, \\ Kazakhstan \\ ${ }^{2}$ Republican Specialized Scientific and Practical Medical Center \\ of Oncology and Radiology, Kazakhstan \\ ${ }^{3}$ Central Asian Cancer Institute, Kazakhstan \\ ${ }^{4}$ Eurasian Institute for Cancer Research, Kazakhstan
}

\begin{abstract}
Correspondence: Alieva Dilfuza, Republican Specialized Scientific and Practical Medical Center of Oncology and Radiology, Tashkent, Uzbekistan, Kazakhstan, Email alievada@yandex.ru
\end{abstract}

Received: November 24, 2018| Published: April 02, 2019

\section{Introduction}

Cervical cancer (cervical cancer) remains one of the global problems of public health and public health. According to the International Agency for the Study of Cancer in the world, about 528,000 new cases of cervical cancer are recorded annually and about 266,000 women die from this pathology. ${ }^{1}$ In this case, the incidence and mortality from cervical cancer has a significant geographical variability ${ }^{2-8}$ and depends on many exogenous and endogenous causes, which of course, in turn, are associated with socioeconomic, demographic factors, reproductive history, etc., as evidenced by numerous studies. ${ }^{9-11}$ In Uzbekistan, as in many countries, cervical cancer also represents one of the urgent problems in oncogynecology. The capital of Uzbekistan is the city of Tashkent, which is the largest city in Central Asia, the center of the Tashkent agglomeration, the main cultural, scientific, political and economic center in Uzbekistan, as well as a transport hub.

The city of Tashkent, one of the largest cities and regions of Uzbekistan, where high rates of oncological morbidity and mortality are noted, which requires further in-depth clinical and epidemiological analysis. In this connection, the scientific and practical interest is the study of morbidity and mortality from cervical cancer in a major megacity of the country.

\section{Material and methods}

The material of the study was data obtained from oncological institutions in Tashkent, concerning new cases of cervical cancer (ICD 10-C53), as well as those who died from this pathology. The data of the State Committee of the Republic of Uzbekistan on Statistics on the number of women in Tashkent and the Cancer Center of Oncology Center were used. The retrospective study for 8 years (2009-2016). According to the standard methods of medical and biological statistics, ${ }^{12,13}$ extensive, age, gross, standardized indicators of morbidity and mortality, and cumulative risk of cervical cancer development have been calculated. Standardized morbidity and mortality rates are calculated in a direct way, the world population standard ${ }^{14}$ is used with recommendations for its calculation. ${ }^{15}$ The morbidity and mortality rates are calculated per $100000(0 / 0000)$ of the female population. The average annual values $(\mathrm{M}, \mathrm{P})$, mean error (m), 95\% confidence interval $(95 \% \mathrm{CI})$, average annual growth rate/ decrease $(\mathrm{Tp} / \mathrm{yb}, \%)$ were determined.

\section{Results and its discussion}

Over 8 years (2009-2016) in Tashkent, 1,190 patients were registered with a first-time diagnosis of cervical cancer and 722 deaths from this pathology. The number of patients and deaths from cervical cancer in the age groups studied is presented in Table 1.

Table I The number of patients and deaths from cervical cancer in the city of Tashkent for 2009-2016

\begin{tabular}{lllll}
\hline \multirow{2}{*}{ Age groups } & \multicolumn{3}{l}{ Sick } & \multicolumn{3}{l}{ dead } \\
\cline { 2 - 5 } & Number & $\%$ & Number & $\%$ \\
\hline $18-44$ & 288 & 24,2 & 113 & 15,7 \\
$45-64$ & 661 & 55,5 & 374 & 51,8 \\
65 and older & 241 & 20,3 & 235 & 32,5 \\
Total & 1190 & 100,0 & 722 & 100,0 \\
Average age & M $\pm \mathrm{m}$ & $95 \% \mathrm{DI}$ & $\mathrm{M} \pm \mathrm{m}$ & $95 \% \mathrm{DI}$ \\
& $54,5 \pm 0,5$ & $53,4-55,5$ & $59,9 \pm 0,7$ & $58,6-61,2$ \\
\hline
\end{tabular}

Table 1 shows that the specific weight of patients with cervical cancer had unimodal growth with a peak in the group of 45-64 years $55.5 \%$, where the number of deaths was also numerous (51.8\%) (Table 1). The average age of patients with cervical cancer in 2009-2016. was $54.5 \pm 0.5$ years and, when aligned, had an undetectable tendency to decrease, and the average annual rate of decline was $\mathrm{Tpr}=+0.6 \%$. The average age of the deceased was $59.9 \pm 0.7$ years, the average annual rate of decline was $\mathrm{Tub}=-0.3 \%$ (Figure 1 ). 


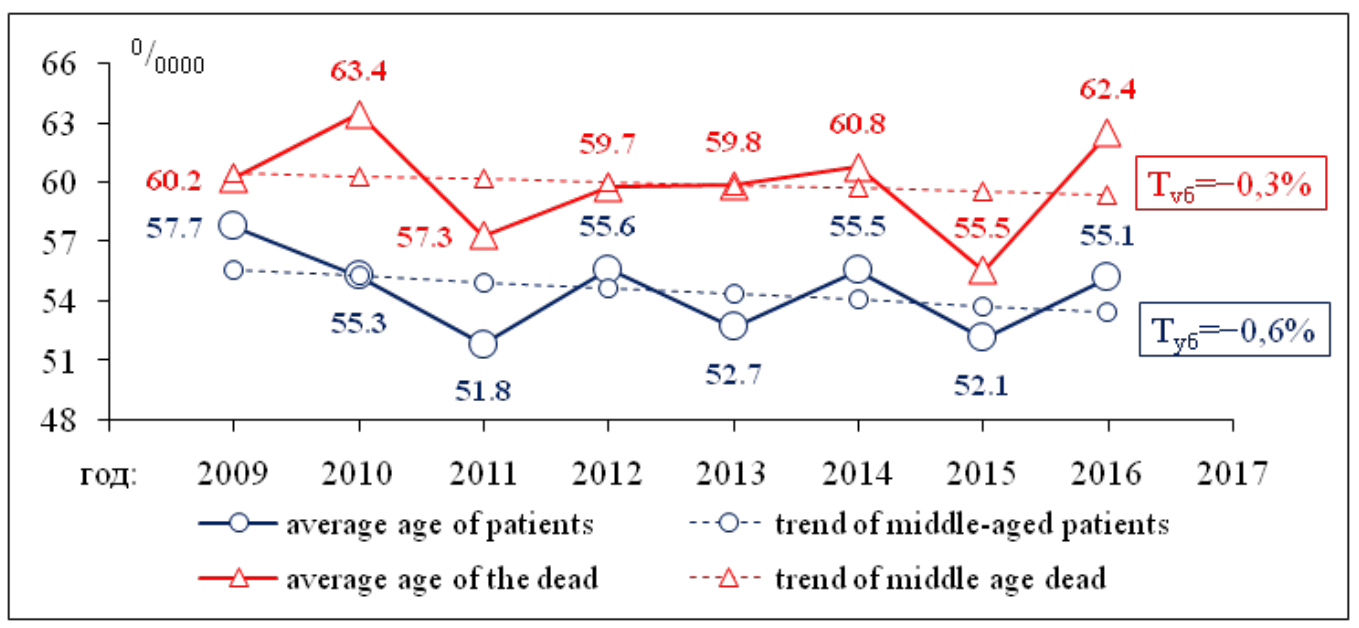

Figure I Dynamics of the average age of patients and deaths from cervical cancer Tashkent for 2009-20I6.

The average annual rough incidence rate of cervical cancer in the capital's residents was $12.5 \pm 0.40 / 0000$ (95\% CI=11.8-13.20/0000), and in dynamics with this indicator leveling, there is a tendency to increase, the average annual growth rate was $\mathrm{Tpr}=+1.8 \%$ (Figure 2 ). An analysis of $95 \%$ confidence intervals of a rough incidence rate of cervical cancer for the years studied showed that they overlapped each other, and the differences were not statistically significant $(p>$ $0.05)$, i.e. The formation of indicators was objectively influenced by the same causal factors. The average annual rough death rate from cervical cancer in the city was $7.6 \pm 0.20 / 0000(95 \% \mathrm{CI}=7.2-8.00 / 0000)$ and in the dynamics tended to decrease, and the average annual rate of decline during equalization was $\mathrm{Tpr}=-0.6 \%$ (Figure 2 ).

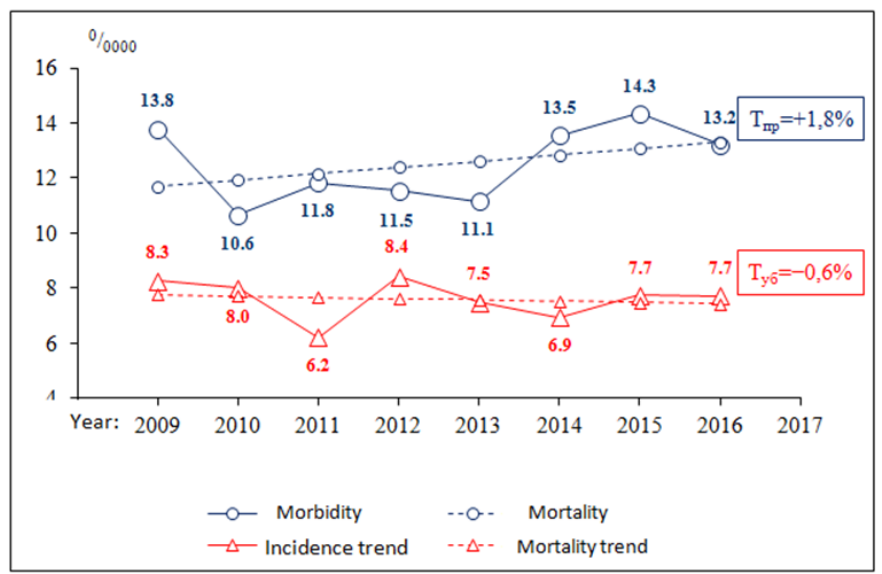

Figure 2 Dynamics of a rough indicator of morbidity and mortality from cervical cancer Tashkent for 2009-2016.

The standardized incidence rate of cervical cancer among residents in Tashkent during the study period averaged $11.4 \pm 0.30 / 0000(95 \%$ $\mathrm{CI}=10.8-12.00 / 0000)$ and was not statistically significantly different from the gross incidence rate (3), since their 95\% CI indicators overlapped each other. Consequently, the age structure of the population of Tashkent did not differ from the world standard of the population. Analysis of $95 \%$ confidence intervals of the coarse incidence of cervical cancer in the studied years showed that they were superimposed on each other, and the differences were statistically insignificant ( $p>0.05)$, i.e. on the formation of indicators objectively influenced by the same causal factors (Figure 3 ).

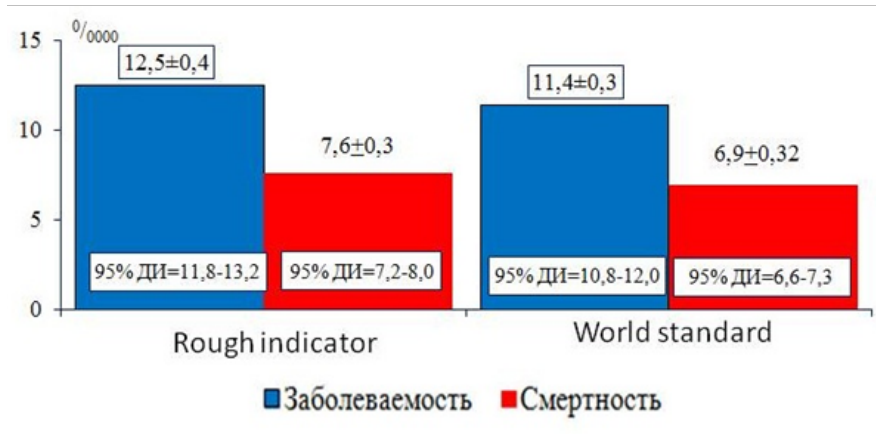

Figure 3 Average annual rates of morbidity and mortality from cervical cancer in the city of Tashkent for 2009-2016.

The average annual gross mortality rate from cervical cancer in the city was $7.6 \pm 0.20 / 0000(95 \% \mathrm{CI}=7.2-8.00 / 0000)$ and in the trend had a tendency to decrease, and the average annual rate of loss in equalization was $\mathrm{Tpr}=-0.6 \%$ (Figure 2). The standardized incidence rate of cervical cancer in female residents in the city of Tashkent for the study period averaged $11.4 \pm 0.30 / 0000(95 \% \mathrm{CI}=10.8-12.00 / 0000)$ and did not statistically significantly differ from the gross incidence rate (3), since their 95\% CI indicators overlapped. Consequently, the age structure of the population of Tashkent did not differ from the world standard of the population. The average annual standardized mortality rate from cervical cancer in Tashkent was $6.9 \pm 0.20 / 0000$ $(95 \%$ CI $=6.6-7.30 / 0000)$ and did not statistically significantly differ from the coarse mortality rate, since their $95 \%$ CI indicators superimposed on each other. In the dynamics, the aligned standardized rates of morbidity tended to increase and the average annual rate of growth was $\mathrm{Tpr}=+1.0 \%$, and the standardized death rates from cervical cancer in Tashkent tended to decrease and the average annual rate of decrease in equalization was Tpr=-1,7\% (Figure 4).

The incidence of cervical cancer in the entire female population of Tashkent for 18-44 years was $7.2 \pm 0.20 / 0000$ (95\% CI $=6.8$ $7.60 / 0000)$. In $45-64$ years, the incidence rate increased by 4.3 times compared with the previous group and amounted to $30.7 \pm 1.50 / 0000$ (95\% CI $=27.8-33.70 / 0000)$. In the age group 65 years and older, the incidence rate was $29.1 \pm 2.60 / 0000(95 \% \mathrm{CI}=24.1-34.10 / 0000)$ (Table 2). Analysis of $95 \%$ CI age indices of cervical cancer in female residents of Tashkent showed that up to 45 years they did not overlap the indicators in older age groups. The reverse picture was 
in the age groups over 45 , where $95 \%$ of the CIs were superimposed on each other, i.e. The differences were statistically insignificant. The average annual mortality rates from cervical cancer in Tashkent grow with age, and the peak of mortality falls on the oldest age group - 65 years and older - 28.4 $\pm 2.20 / 0000$ (Table 2). At the same time, analyzing the $95 \% \mathrm{CI}$ of the age-specific mortality rates, it was established that they did not overlap each other, i.e. the difference was statistically significant $(\mathrm{p}<0.05)$, which indicated the influence of various factors affecting the formation of mortality rates from cervical cancer in different age periods. The trends in the age-specific incidence rates tended to increase in $18-44$ years $(\mathrm{Tpr}=+2.6 \%)$ and at 45-64 years $(\mathrm{Tpr}=+2.8 \%)$, and the decline was observed in the older age group - 65 years and older (Tub=-5.7\%) (Table 2). Trends in the age-specific mortality rates from cervical cancer in Tashkent have tended to decrease in 18-44 years ( $\mathrm{Tub}=-2.6 \%$ ), 65 years and older ( $\mathrm{Tub}=-5.5 \%)$, and in 15-44 years, mortality had a tendency to increase $(\mathrm{Tpr}=+1.2 \%)$ (Table 2). Analysis of the ratio of mortality to morbidity showed that the highest values approaching unity were established in the age group 65 years and over - 0.98 (Figure 4), and in Tashkent as a whole, which is 0.61 . It is established that the incidence and mortality from cervical cancer in Tashkent remain at a rather high level. Undoubtedly, the formation of these indicators in recent years has been influenced by the implementation of the reform processes in the country's healthcare system that have taken place in recent years, aimed at early diagnosis and prevention of oncology. There are also questions: "Why is the morbidity and mortality in the age group of 45-64?"; "What is the reason for the high rate of decrease in morbidity and mortality of cervical cancer in the age of 65 and older?"; "Why does the ratio of mortality to morbidity approach 1 in the same age group?". Undoubtedly, this is due to the problems of registration and registration of patients. We can not give singlevalued and full answers within the framework of this article, since this requires further in-depth study and analysis.

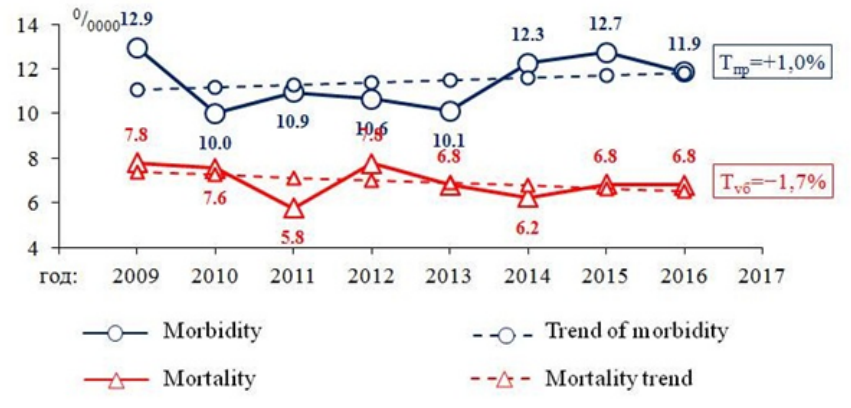

Figure 4 Standardized rates of morbidity.

Table 2 Age indicators of morbidity and mortality from cervical cancer in female residents of Tashkent for 2009-2016

\begin{tabular}{|c|c|c|c|c|c|c|}
\hline \multirow{2}{*}{ Age groups } & \multicolumn{2}{|c|}{ Morbidity, ${ }^{\%}{ }_{0000}$} & \multirow{2}{*}{ Tpr / ub,\% } & \multicolumn{2}{|c|}{ Mortality, $\%_{0000}$} & \multirow{2}{*}{ Tpr / ub,\% } \\
\hline & $\mathrm{P} \pm \mathrm{m}$ & $95 \% \mathrm{DI}$ & & $\mathrm{P} \pm \mathrm{m}$ & $95 \% \mathrm{DI}$ & \\
\hline $18-44$ & $7,2 \pm 0,2$ & $6,8-7,6$ & $+2,6$ & $2,6 \pm 0, I$ & $2,3-2,8$ & $-2,6$ \\
\hline $45-64$ & $30,7 \pm 1,5$ & $27,8-33,7$ & $+2,8$ & $17,4 \pm 0,7$ & $16,|-| 8,7$ & $+1,2$ \\
\hline 65 and over & $29,1 \pm 2,6$ & $24, I-34, I$ & $-5,7$ & $28,4 \pm 2,2$ & $24,0-32,8$ & $-5,5$ \\
\hline
\end{tabular}

We can not give single-valued and full answers within the framework of this article, since this requires further in-depth study and analysis. Thus, the results of the epidemiological assessment of morbidity and mortality from cervical cancer in Tashkent show the current trend and the need for further in-depth epidemiological studies of cervical cancer (morbidity, mortality, early diagnosis, neglect, morphological verification, cytological screening results, evaluation of treatment methods, indicators survival, etc.) on a national scale. The results of epidemiological studies can be recommended for use in monitoring and evaluating cancer control activities in the country, and making targeted management decisions.

\section{Conclusion}

a) In Tashkent, for the period under study, there were 1,191 new cases of cervical cancer and 722 deaths from this pathology. The average age of patients was 54.5 years, the deceased - 59.9 years, while in the dynamics there is an indistinct tendency to "rejuvenate";

b) The incidence of cervical cancer in Tashkent was estimated at a rough estimate of 12.50/0000 and the world standard of 11.40/0000;

c) Mortality from cervical cancer in Tashkent amounted to $7.60 / 0000$ in the rough estimate and $6.90 / 0000$ in the standardized indicator;

d) Age indices of cervical cancer showed unimodal growth with peak incidence in 45-64 years - 30.70/0000 and peak mortality - 65 years and older - 114.20/0000. In this case, the ratio of mortality to morbidity in this group had a maximum value of 0.98 ;

e) In the dynamics, the age-specific incidence rates had a different tendency and on the whole it affected the overall trend (Tpr=+ $1.8 \%)$

f) The trends of mortality rates as a whole declined (Tub $=-0.6 \%$ ), which was due to a decrease in the age groups 18-44 $(\mathrm{Tpr}=-$ $2.6 \%)$, as well as 65 years and older $(\mathrm{Tpr}=-5.5 \%)$.

\section{Acknowledgments}

None.

\section{Conflicts of interest}

Author declares that there is no conflict of interest.

\section{References}

1. Ferlay J, Soerjomataram I, Ervik M, et al. GLOBOCAN 2012 v1.0, Cancer Incidence and Mortality Worldwide. IARC Cancer Base. International Agency for Research on Cancer. 2013.

2. Forman D, Bray F, Brewster DH, et al. Cancer Incidence in Five Continents. International Agency for Research on Cancer. 2014;10:164.

3. Igisinov N. Ethnic and age variation of Cancer of the Reproductive System in Women of Kyrgyzstan. Asian Pac J Cancer Prev. 2004;5(2):217-222.

4. Igisinov NS, Igisinova GS, Satekasina GD. Epidemiology of uterine cervical cancer in selected regions of Kyrgyzstan. Oncology and Radiology Kazahstana. Asian Pac J Cancer Prev. 2005;(10):7-14. 
5. Kudryavtsev IY. Statistics of malignant neoplasms of the female reproductive system in the Navoi region of the Republic of Uzbekistan: morbidity, mortality and socio-economic damage. Blokhina RAMS 2009;20(2):28-33.

6. AN Abdikhakimov, TA Koshkin. The first experience of screening for cervical cancer with the definition of human papillomavirus in the Central Asian region. Blokhin RAMS. 2010;21(3):20-23.

7. Igissinov N, Nuralina I, Igisssinova G, et al. Epidemiological Aspects of Morbidity and Mortality from Cervical Cancer in Kazakhstan. Asian Pac J Cancer Prev. 2012;13(5):2345-2348.

8. Tilliashahov MN, Islamov Kh D, Aliyev DA. The state of the oncological service of Uzbekistan and the prospects for its development. Eurasian Oncological Journal. 2017;1:24-29.

9. Zaridze DG. Epidemiology, mechanisms of carcinogenesis and cancer prevention. Probl Clinic Medicine. 2005;2:10-16.
10. Mohanty G, Ghosh SN. Risk factors forcancerofcervix, status. Arch Gynecol Obstet. 2015;291(2):247-249.

11. Pimple S, Mishra G, Shastri S. Global strategies for cervical cancer prevention. Curr Opin Obstet Gynecol. 2016;28(1):4-10.

12. Merkov AM, Polyakov LE. Sanitary statistics. Leningrad Medicine. 1974: 384 p.

13. Glantz S. Biomedical statistics. 2009; 460 p.

14. Ahmad OB, Boschi-Pinto C, Lopez AD, et al. Age standardization of rates: a new who standard. GPE Discussion Paper Series. World Health Organization. 2001:31.

15. Recommendations of the National Cancer Institute (USA) on the use of the World Standard (WHO 2000-2025). 